\title{
The passing of the shift in aircraft mainte- nance - a task that produces deaths
}

\author{
Reginaldo Campos. ${ }^{11,}$, Edgard Martins ${ }^{2}$; Marcelo M. Soares ${ }^{3}$ \\ ${ }^{I}$ Universidade Federal de Pernambuco-Depto de Design-CAA - Caruaru- Pernambuco- Brasil, \\ regiscampos3@gmail.com \\ ${ }^{2}$ UFPE- Universidade Federal de Pernambuco- Depto de Design-CAA - Recife- Pernambuco- Brasil; \\ marcelo2@nlink.com.br \\ ${ }^{3}$ UFPE- Universidade Federal de Pernambuco- Depto de Design-CAA - Recife- Pernambuco- Brasil;
}

\begin{abstract}
Maintenance tasks, especially in heavy maintenance, may not be completed in a single shift. Aircraft maintenance technicians often take work in progress by colleagues, and spend the incomplete work for a change of team. The need for accuracy and efficiency of information transfer in many cases, without having time to have a meeting to pass the service is a crucial aspect of maintenance work. The ideal shift change can occur normally before delivery and continues to proceed normally after delivery. Although a shift change create challenges for communication, they also offer opportunities to detect and correct errors, where the task of delivery is an opportunity to identify the problem and fix it. In this case, the task was done correctly the first round, however, a problem began when the second round took. One example is a case in which the first round have removed a defective part for replacement and let the component of aircraft at end of turn with problems. Instead of ordering and installation of an operational component, the second round was then reinstall the faulty component, not realizing he had information about the problem attached.
\end{abstract}

Keywords: Applied Ergonomics; Reliability; Flight Security

\section{Introduction}

Many maintenance tasks, especially in heavy maintenance, may not be completed in a single shift. Aircraft maintenance technicians often take work in progress by colleagues, and spend the incomplete work for a change of team. The need for accuracy and efficiency of information transfer in many cases, without having time to have a meeting to pass the service is a crucial aspect of maintenance work. The ideal shift change can occur normally before delivery and continues to proceed normally after delivery. Although a shift change create challenges for communication, they also offer opportunities to detect and correct errors, where the task of delivery is an opportunity to identify the problem and fix it. In this case, the task was done correctly the first round, however, a problem began when the second round took. One example is a case in which the first round have removed a defective part for replacement and let the component of aircraft at end of turn with problems. Instead of ordering and installation of an operational component, the second round was then reinstall the faulty component, not realizing he had information about the problem attached. Studying the operational aspects of aircraft in transit in relation to the routine of daily operations at airports, some work done for maintenance, inspection and general condition of the aircraft, fuel, tire changes, among others, though routine, are extremely important . Some environmental factors like temperature, light and noise can influence directly or indirectly in the execution of the tasks of aircraft mechanic. This pressure increases with the downtime of the aircraft 
is in transit, where delays can often cause problems in the continuity of travel time that the crew can stay aboard, fines and other operational problems. We can also mention the users who are directly affected in case of delays.

\section{Contextualization}

Any aircraft before leaving the ground is a must for maintenance and / or inspection. There is always a big debate about the responsibility of the causality of the major air accidents such as occurred with the TAM Airbus 320 and the Focker 100 on Congonhas Airport or the GOL on the Amazon Forest, which collided in the air with the plane Embraer Legacy 600. All have killed all occupants of the aircraft of TAM and GOL Airlines, including some people on the ground, according to reports widely disseminated in the media and also investigated by CENIPA (National Center for Research and Prevention of Accidents) through their investigative reports.

Hardly a single causal factor is the determinant for the occurrence of an event of this nature. It is known that various components are operating-rational and situations that occur simultaneously or successively in an aircraft, which converge at the moment of the accident fatalities that end up generating operational situations when they begin to have problem as faulty operation, failure of equipment failures or maintenance [1].

This artifact after its delivery to the operation, will move to the professionals who must keep it in full working order and especially security. This occurs in conjunction with the other two components that constitute the pillars of a safe aircraft, which are the Production Project, the Steering and Support of Earth, as shown in figure 1. The tasks of preventive and corrective maintenance performed on the day to day by the aviation mechanics, which virtually guarantee the safe operation of these aircraft.

Figure 1 - Components that place and maintain an aircraft in flight (Source: Based on the figure of Martins, 2006, 2010)

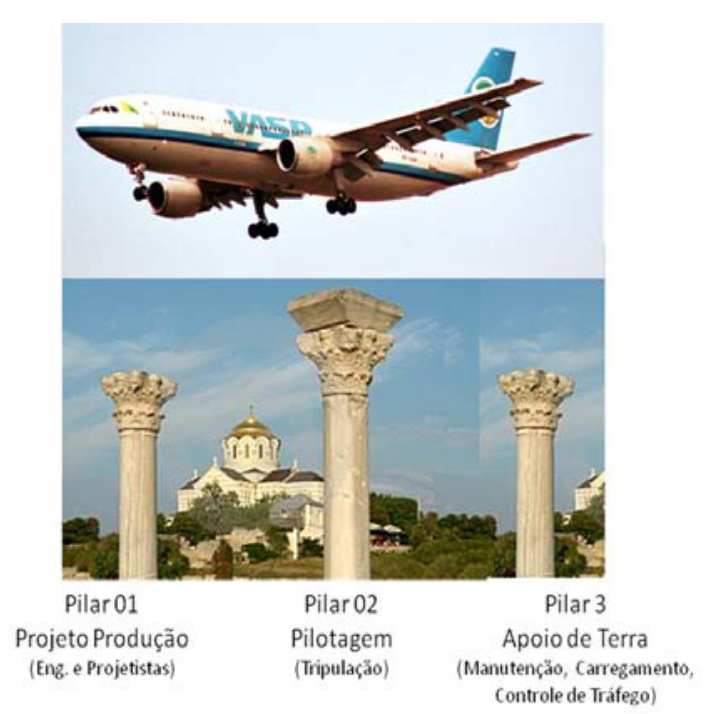

The experts in aircraft maintenance, on-Through the observation, study, learn and experience ram to perform the tasks as accurate as possible, and thus anticipate and correct any defects. However, this path inserted in the quest for technical perfection of the aircraft by all 03 Pillars of Sustemptation to aviation safe, you are invariably the aircraft mechanics who work on a daily desing operations. The mechanics are also responsible directly and indirectly by the crew and passengers are on board and that in case of catastrophic accidents, who pays the highest price, which is often life itself [2].

\section{Problematization}

The job of aircraft mechanic is subject to situations that can lead to induction of a mistake, whether of an operational or human error, such as distraction, individual errors, lack of procedures, cognitive problems, poorly designed manuals, among others. Factors related to human error and problems of perception, memory lapses, slips from a routine procedure, even for erroneous assumptions end up leading the technical mistakes that can end up causing accidents or incidents with the most diverse consequences. Violations of procedures can target the most diverse situations that include the task of an aircraft mechanic, and in some cases the consequences are catastrophic. There are various forms of pressure that are exerted on these professionals, whether for cost or time for the airlines not to delay their flights, or by running the task, they 
usually have to be at the limit of perfection and excellence.

The execution of any task in aviation so careless or even wrong can result in incidents and even tragedies that are widely publicized in the media ?

\section{Applications}

Errors in the shift change can be particularly dangerous, as shown by an accident involving an aircraft of the Embraer Brasilia-Eagle Lake, Texas in 1991, which resulted in 14 deaths. The night before the accident, the maintenance work was carried out which involved the removal of screws on the upper surface of the left tail of Brasilia. However, the work was only partially completed, when there was a shift change and no record was made to show that the task had been started. The maintenance workers who entered the turn signed the release of the plane to return to work, unaware that bolts were missing that were critical of the tail section. The leading edge of the horizontal stabilizer separated from the aircraft in flight. Prospective studies using an analytical method in the setting of aircraft maintenance, conducted in our work for the degree of Master, show that the transfer of information between shifts is more effective when looking at the problems, solutions and intentions. The studies conducted show that:

a The shift change occurs ideal, where the task is proceeding normally before delivery and continues to proceed normally after delivery.

b The task is off the track during the first round, but the delivery is an opportunity to identify the problem and fix it. Although a shift change create challenges for communication, they also offer opportunities to detect and correct errors.

c The task was performed correctly by the first round, however, a problem began when the second round took. One example is a case in which the first round have removed a defective part for replacement and let the component of aircraft at end of turn with problems. Instead of ordering and installation of an operational component, the second round was then reinstall the faulty component, not realizing he had information about the problem attached d. An error occurred in the first round and then was continued by the staff of the second round. A healthy level of skepticism could have helped ensure that the change of entry, examining the work of change of output and make assumptions as possible about the job status.

The maintenance of a general is now seen in recent years differently in production processes, bringing further analysis of the relationship between human and machine. An example that we mention these tests was the cognitive aspect of how human beings react and behave in front of an artifact during maintenance. These tests are showing every day the importance and necessity of maintaining the productive processes. With the increasing production demand and the aggressive competition in the market, it is not permissible for machines that serve the means of production, be it products or services, such as aviation, to stop producing or even to produce a capacity of less than projected. The protection takes on a role of paramount importance not only in manufacturing processes, but guaranteed to be essential services, comfort and well-being of rivers usual handling these machines or are they the serve.

Maintenance professionals are subject to various interferences of the environment where it carries out its task. Several factors such as environmental, organizational personal or interfere directly or indirectly during the execution of their maintenance, is corrective, preventive or predictive

\section{Conclusions}

Authorities recommend that a personal meeting is made by people who do the work during the shift change, rather than verbal scores filtered through a link in shifts, as is the case today in the premises of many companies during maintenance. In many cases, the information content of the transfer, either through documents or personal meetings for interaction is limited to describing the steps of the task completed by the change in output. Studies in a range of industries also show that the transfer of information between shifts is most effective when it captures the problems, possible solutions and intentions, not just the description of what was accomplished. The dissection of the deep problems is not an accepted practice in aviation maintenance. Personal meetings during the hand-over is a standard operating procedure in many high-risk industries such as nuclear energy, offshore oil, and air traffic control, are still relatively rare in aircraft maintenance. 


\section{References}

[1] Filho, José Aires de Castro - Learning Objects - Article and Lecture Notes, j.castro @ ufc.br, 2007
[2] Martins, Edgar Thomas - Monograph Masters-A Critical Study of Responsibility of Pilot in Aircraft Accident, 2006, UFPE 